\title{
Universiteit
}

Leiden

The Netherlands

\section{C NMR study of the grafting of 13C labeled maleic anhydride onto PE, PP and EPM}

Heinen, W.; Duin, M. van; Rosenmuller, C.H.; Wenzel, C.B.; Groot, H.J.M. de; Lugtenburg, J.

\section{Citation}

Heinen, W., Duin, M. van, Rosenmuller, C. H., Wenzel, C. B., Groot, H. J. M. de, \& Lugtenburg, J. (1998). 13C NMR study of the grafting of 13C labeled maleic anhydride onto PE, PP and EPM. Macromolecular Symposia, 129(1), 119-125. doi:10.1002/masy.19981290111

Version: $\quad$ Publisher's Version

License: $\quad$ Licensed under Article 25fa Copyright Act/Law (Amendment Taverne)

Downloaded from: $\quad$ https://hdl.handle.net/1887/3239383

Note: To cite this publication please use the final published version (if applicable). 


\title{
${ }^{13} \mathrm{C}$ NMR STUDY OF THE GRAFTING OF ${ }^{13} \mathrm{C}$ LABELED MALEIC ANHYDRIDE ONTO PE, PP AND EPM
}

\author{
Wouter Heinen*, and Martin van Duin \\ DSM Research, P. O. Box 18, 6160 MD, Geleen, The Netherlands \\ Carola H. Rosenmöller, Cornelia B. Wenzel, Huub J.M. de Groot, and Johan \\ Lugtenburg \\ Leiden Institute of Chemistry, Gorlaeus Laboratories, P. O. Box 9502, 2300 RA, \\ Leiden, The Netherlands
}

\begin{abstract}
The chemical structure of polyolefins grafted with maleic anhydride (MA) has been the subject of much speculation, but thorough experimental studies are rare. MA with $99 \%{ }^{13} \mathrm{C}$ in the double bond was synthesized and grafted onto $\mathrm{PE}$, EPM and PP in the melt and solution. 1D INADEQUATE ${ }^{13} \mathrm{C}$ NMR spectroscopy was used to characterize the products. Saturated, monomeric MA graft structures are formed. Only for grafted PE short MA oligomers are demonstrated. Grafting occurs on secondary and tertiary carbons depending on the composition of the polyolefin. For PP a new, unsaturated MA graft structure on the polymer chain terminus is identified. All graft structures are rationalized using a simple grafting mechanism.
\end{abstract}

\section{INTRODUCTION}

Grafting of maleic anhydride (MA) provides a relatively straightforward and inexpensive route for increasing the polarity and reactivity of polyolefins (Ref.1). Grafting of MA is usually achieved via a free radical reaction or in the case of unsaturated polymers via the ene reaction. The grafted products find widespread application as adhesion promoters (multilayer foils, metal bonding and coupling agent for glass fibers) or compatibilizers for polyamide blends. Many studies have been published on MA functionalization, but most of them are limited to practical procedures for preparation (Ref.2). The chemical structure of the grafted 
material has been the subject of much speculation, but thorough experimental studies are rare. As a result, the mechanism of grafting is still a matter of debate and it remains very difficult to optimize the structure of MA grafted polymers for a certain application.

Here we present a study on the free radical grafting of MA, ${ }^{13} \mathrm{C}$ labeled at both olefinic positions $\left(\left[2,3-{ }^{13} \mathrm{C}_{2}\right] \mathrm{MA}\right)$, onto a series of polyolefins. ${ }^{13} \mathrm{C}$ NMR is used for elucidation of the graft structures. Several structural features are addressed: saturation of the MA graft, monomeric versus oligomeric MA grafting and position of attachment to the polyolefin chain. Earlier, Glans and Akkapeddi used a similar approach to investigate the chemical structure of PPO-g-MA (Ref.3).

\section{EXPERIMENTAL}

$\left[2,3-{ }^{13} \mathrm{C}_{2}\right] \mathrm{MA}$ was synthesized starting from commercial $\left[2-{ }^{13} \mathrm{C}\right]$ acetic acid (overall yield: $44 \%$ ) (Ref.4). The polyolefins are either commercially available or were especially prepared in our laboratory. MA was melt grafted in a home-built, small scale, fully intermeshing, corotating twin screw extruder with a recirculation channel. Typically, $3.5 \mathrm{~g}$ polyolefin, $5 \mathrm{wt} \%[2,3-$ ${ }^{13} \mathrm{C}_{2}$ ]MA and $0.25 \mathrm{wt} \%$ tert-butyl cumyl peroxide was mixed for $5 \mathrm{~min}$. at $170{ }^{\circ} \mathrm{C}$. Solution grafting was carried out in biphenyl for $1 \mathrm{hr}$. at $170^{\circ} \mathrm{C}$ using di-tert-butyl peroxide as initiator. Biphenyl was used as solvent, since it does not contain labile hydrogens. Before further analysis, unreacted MA was removed at elevated temperature and reduced pressure.

${ }^{13} \mathrm{C}$ NMR spectra were recorded on a Bruker MSL 400 spectrometer $\left(\mathrm{C}_{2} \mathrm{D}_{2} \mathrm{Cl}_{4} ; 120^{\circ} \mathrm{C}\right)$. 1D INADEQUATE experiments (Ref.5) were optimized for $J_{C \cdot c}=34 \mathrm{~Hz}$ to separate the signals of ${ }^{13} \mathrm{C}-{ }^{13} \mathrm{C}$ spin pairs from the natural abundance background. In Fig. 2 magnitude calculated spectra are shown for optimum, visual clarity. The ${ }^{13} \mathrm{C}$ NMR signals were assigned aided by ${ }^{13} \mathrm{C}$ NMR spectra of a set of low molecular, alkyl substituted succinic anhydrides (or chemical shift increments, derived from these models) (Ref.6).

\section{RESULTS AND DISCUSSION}

Figures $1 \mathrm{a}$ and $\mathrm{b}$ nicely show the ${ }^{13} \mathrm{C}$ NMR signal enhancement due to ${ }^{13} \mathrm{C}$ enrichment of the MA used. In addition, 1D INADEQUATE ${ }^{13} \mathrm{C}$ NMR results in suppression of the polyolefin backbone signal (Fig. 1c). Fig. 2 shows the 10 INADEQUATE spectra for the various polyolefins grafted with labeled MA in the melt and in solution. They are placed in top-down order of decreasing $E: P$ ratio, with the spectrum of the solution grafted material below that of the melt grafted product. It is clear that decreasing the E:P ratio leads to a decreased MA graft yield (decreased signal to noise ratio). Grafting in solution results in increased MA graft contents. 


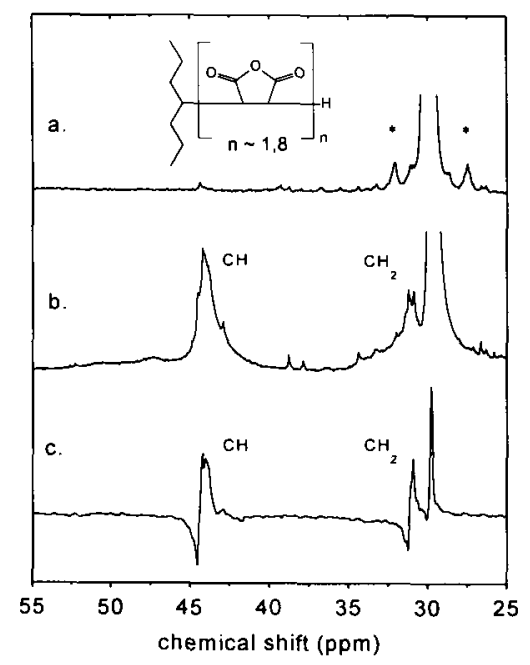

Fig. $1 .{ }^{13} \mathrm{C}$ noise decoupled NMR spectra of HDPE grafted in the melt with a. MA, and b. $\left[2,3-{ }^{13} \mathrm{C}_{2}\right] \mathrm{MA} ;$ c. spectrum of HDPE grafted with $\left[2,3-{ }^{13} \mathrm{C}_{2}\right] \mathrm{MA}$ obtained using 1D INADEQUATE ${ }^{13} \mathrm{C}$ NMR. The asterisks denote signals resulting from incomplete proton decoupling.

Fig. 2. Magnitude calculated 1D INADEQUATE ${ }^{13} \mathrm{C}$ NMR spectra of $P E$, EPM and $P P$, grafted with $\left[2,3 \cdot{ }^{13} \mathrm{C}_{2}\right] \mathrm{MA}$ in the melt or in biphenyl. Residual responses from unlabeled sites are marked with an asterisk. Roman numerals refer to the structures in Fig. 4.

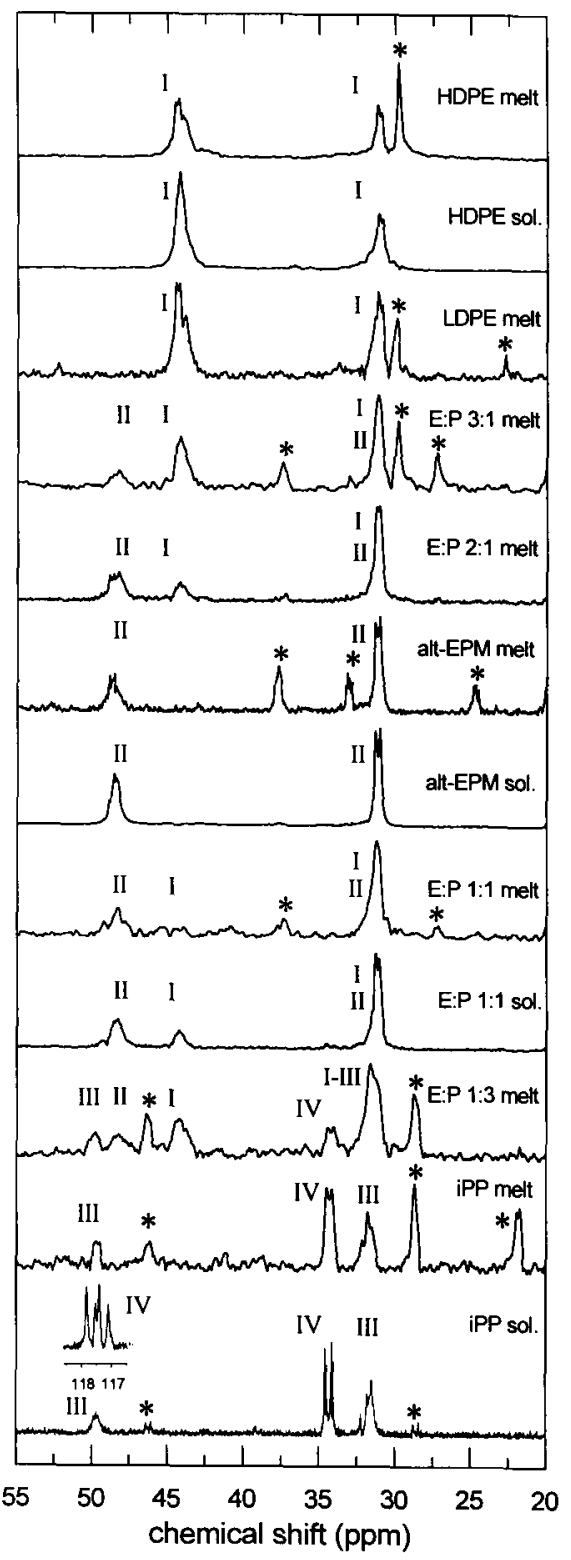


The ${ }^{13} \mathrm{C}$ NMR spectrum of HDPE melt functionalized with MA contains two signals due to the presence of grafted MA, viz. at 31 and $44 \mathrm{ppm}$. The chemical shifts agree very well with those of the hept-4'-ylsuccinic anhydride reference compound at $\delta 29.8$ and $43.2 \mathrm{ppm}$ (Fig.3a), resp. The splitting of $34 \mathrm{~Hz}$ for the high field signal is typical for a $\mathrm{sp}^{3}-\mathrm{sp}^{3}{ }^{13} \mathrm{C}-{ }^{13} \mathrm{C}$ one bond $J$ coupling. The intensity of the methine signal at $44 \mathrm{ppm}$ is larger than that of the methylene at $31 \mathrm{ppm}$. The width of the methine signal is relatively large. It is therefore concluded that in HDPE-g-MA prepared in the melt MA is grafted as short oligomers with an average degree of polymerization of about 2 (Fig.4: I). Apparently, oligomeric grafts are still formed at a temperature $\left(170^{\circ} \mathrm{C}\right)$ well above the ceiling temperature of the MA monomer $\left(108^{\circ} \mathrm{C}\right.$ (Ref.7)) The spectra of HDPE grafted in solution with MA and that of melt grafted LDPE ( 25 wt.\% octene) are rather similar to that of melt grafted HDPE, indicating similar chemical structures. However, the average length of the MA graft is more close to unity. For solution grafting MA is completely dissolved on a molecular level in biphenyl, resulting in monomeric grafts.

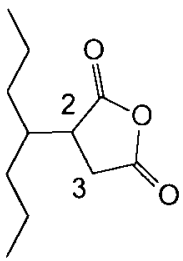

a.

$\mathrm{C}_{2}$

$\mathrm{C}_{3}$

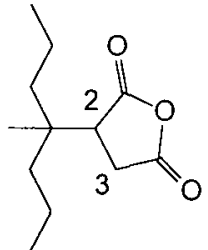

b.

47.9

30.5

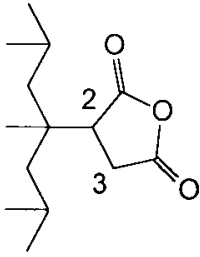

c.

48.3

30.2

Fig. 3. Alkyl substituted succinic anhydride model compounds representing possible graft structures in a. $P E$, b. alt-EPM, and c. PP, and the chemical shifts of the methylene and methine ring carbons (in ppm) (Ref.6).

In the spectra of MA grafted LDPE and EPM's with a relatively low propene $(P)$ content signais as for HDPE are observed, indicating similar structures with MA monomeric units grafted to methylene carbons (Fig . 4: I). The spectra of MA grafted EPM's with an intermediate $\mathrm{P}$ content contain an additional ${ }^{13} \mathrm{C}$ signal at $49 \mathrm{ppm}$, which is rather close to the anhydride ring methine chemical shift of the (4'-methylhept-4'-yl)succinic anhydride model compound at 47.9 ppm (Fig.3b). So, it is concluded that for these EPM's grafting not only occurs on secondary carbons of the polyolefin chain, but also on the tertiary carbons (Fig.4: II). Surprisingly, the spectrum of MA grafted alt-EPM shows that only MA grafts attached to tertiary carbons are present; and none or very few attached to secondary carbons are present. From the integral of the label signals it is concluded that only monomeric graft species are formed. The chemical shift dispersion of the low field signal is attributed to atacticity in the polymer backbone. 
The ${ }^{13} \mathrm{C}$ NMR spectrum of IPP grafted in solution with MA contains two sets of signals. The first one with chemical shifts at 32 and $50 \mathrm{ppm}$ probably is due to a single MA unit grafted to a tertiary carbon of the PP chain. These chemical shifts roughly match those of the corresponding carbon atoms in the $\left(2^{\prime}, 4^{\prime}, 6^{\prime}\right.$-trimethylhept-4'-yl)succinic anhydride model compound at 30.2 and $48.3 \mathrm{ppm}$, resp. (Fig.3c) The present findings are in conflict with those of De Roover et al. (Ref.8) who suggest that oligomeric and even polymeric MA grafts are attached exclusively to PP chain ends. However, such structures would give rise to methine signals at $45 \mathrm{ppm}$, which are not observed. The mechanim of Gaylord, describing the grafting of MA oligomers to PP (Ref.9), is also not substantiated.

A second pair of ${ }^{13} \mathrm{C}$ labels resonates at $\delta \sim 34$ and $\sim 118 \mathrm{ppm}$ and is assigned to an isomeric graft mixture ( $E$ and $Z$ configurations) of a single MA monomer linked to a PP chain end by a double bond (Fig.4: IV). This structure is confirmed by a 2D J-resolved NMR spectrum, indicating that two hydrogens are attached to the anhydride methylene and none to the unsaturated anhydride carbon. This proves that PP chain scission does occur, but the actual graft structure can only be explained by chain scission after grafting of MA to PP. For $P$ rich EPM's resonances are observed at $31,34,44,48,50$ and $117 \mathrm{ppm}$, showing that here all four different graft structures (Fig.4: I, II, III and IV) have been formed. Finally, we have found no indications for MA acting as a crosslink between two polymer chains as suggested by Gaylord and Mehta (Ref.10).

The elucidation of the chemical structures of the series of MA grafted polyolefins allows a discussion of the mechanisms of free radical grafting of MA (Fig.4). The reaction sequence consists of hydrogen abstraction from the polyolefin backbone by primary radicals derived from the peroxide initiator. This is followed by addition of MA to the macroradical, propagation (only in the case of HDPE) and finally chain transfer, resulting in a saturated MA graft, or chain scission, resulting in an itaconic anhydride-like graft structure (only in the case of PP). Finally, termination may occur through combination or disproportionation of two macroradicals.

In the case of PE and EPM's with low P contents hydrogen abstraction will occur mainly at the secondary carbons, resulting in graft structure I (Fig.4). For alt-EPM only grafting on tertiary carbons is observed (Fig.4: II), suggesting selective hydrogen abstraction from these carbons. For EPM's with high $P$ contents and iPP rather selective grafting on tertiary carbons is observed (Fig.4: III). In addition, this graft structure can be involved in PP chain scission, resulting in a MA monomer attached to the PP chain end via a double bond (Fig.4: IV). 
Grafting onto E-sequences:

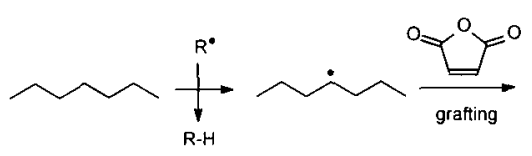<smiles>CCCC(CCC)C1CC(=O)OC1=O</smiles><smiles>CC(C)C1CC(=O)OC(=O)C1</smiles><smiles>CCCC(CCC)C1C(=O)OC(=O)C1C1C(=O)OC(=O)C1C</smiles>
$\underbrace{1}$

ion $R-H \underset{\substack{\text { nydrogen } \\ \text { transier }}}{\rightarrow R^{*}}$

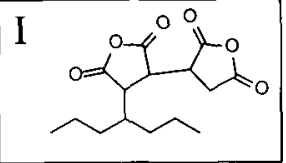

Grafting onto isolated $P$ units:

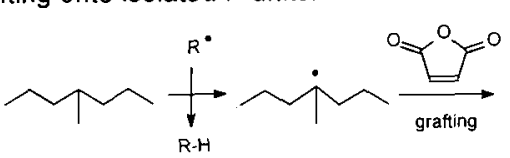<smiles>CCCC(C)(CCC)C1C(=O)OC(=O)C1C</smiles>

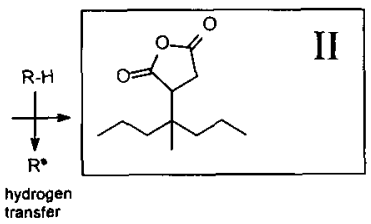

Grafting onto P-sequences:

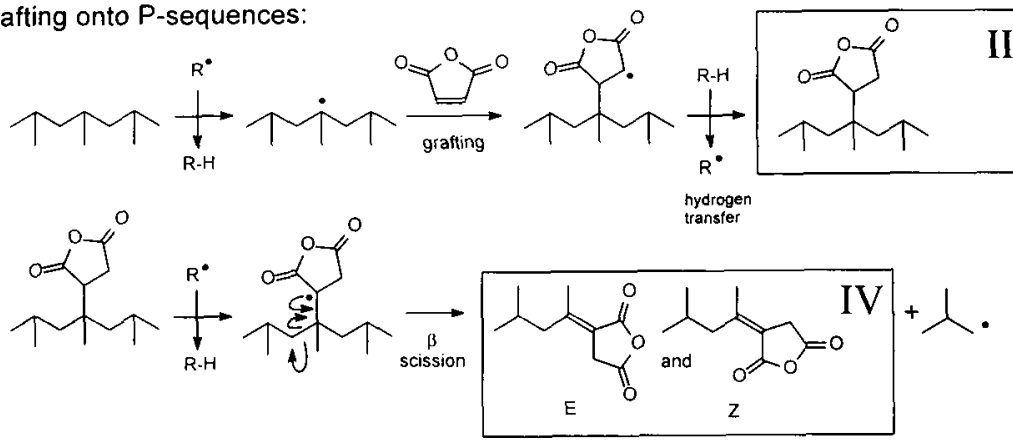

Fig. 4. Mechanisms for grafting of MA onto PE, alt-EPM and iPP.

The observation that, besides structure IV, only saturated MA grafts exist, indicates that chain transfer is occurring through hydrogen abstraction. The length of the MA graft is determined by the efficiency of the hydrogen transfer, which terminates the MA propagation reaction. For HDPE in the melt oligomeric MA grafts are formed. However, P containing polyolefins contain labile, tertiary hydrogens. Thus, hydrogen transfer is can occur and predominantly or only monomeric grafts are formed.

The difference in MA graft yields for melt and solution grafted products is easily rationalized by the different experimental recipes and/or procedures. More important is that the graft structures are similar. 


\section{CONCLUSIONS}

The structures of polyolefins grafted with MA have been elucidated using ${ }^{13} \mathrm{C}$ NMR spectroscopy in conjunction with specific isotope labeling of MA. Placing two adjacent labels in the MA monomer allows the application of the 1D INADEQUATE ${ }^{13} \mathrm{C}$ NMR technique, resulting in spectra containing dominant signals of MA grafts. MA attaches to HDPE in the melt as mono- and oligomers. In LDPE, EPM's and iPP only monomeric MA grafts are formed, due to the presence of labile, tertiary hydrogens. Long methylene sequences $(>3)$ are required for grafting onto secondary carbons. Saturated MA grafts have been identified with the exception of a new, unsaturated MA graft structure for iPP, resulting from grafting followed by chain scission.

\section{ACKNOWLEDGMENTS}

J. Beulen, M. Bulters, P. Elemans, C. Erkelens and T. Veermans are gratefully acknowledged for their contributions to this work.

\section{REFERENCES}

(1) B. C. Trivedi and B. M. Culbertson, "Maleic Anhydride", Plenum Press, New York (1982).

(2) M. Xanthos (Ed.), "Reactive Extrusion - Principles and Practice", Hanser Publishers, Munich (1992).

(3) J. H. Glans and M. K. Akkapeddi, Macromolecules, 24, 383 (1991).

(4) W. Heinen, C. H. Rosenmöller, C. B. Wenzel, H. J. M. de Groot, J. Lugtenburg and M. van Duin, Macromolecules, 29, 1151 (1996).

(5) A. Bax, R. Freeman and S. P. Kempsell, J. Am. Chem. Soc., 102, 4849 (1980).

(6) W. Heinen, thesis. Leiden 1996 (paper to be published).

(7) K. E. Russell, J. Polym. Sci., Part A, Polym. Chem., 33, 555 (1995).

(8) B. De Roover, M. Sclavons, V. Carlier, J. Devaux, R. Legras, and A. Momtaz, J. Polym. Sci., Part A, Polym. Chem., 33, 829 (1995).

(9) N. G. Gaylord and M. K. Mishra, J. Polym. Sci., Polym. Lett. Ed., 21, 33 (1983).

(10) N. G. Gaylord and M. Mehta, J. Polym. Sci., Polym. Lett. Ed., 20, 481 (1982). 